\title{
Mechanical performance of FRP-RC flexural members subjected to fire conditions
}

\author{
Kostiantyn Protchenko ${ }^{1}$, Elżbieta Szmigiera ${ }^{2}$, \\ Marek Urbański ${ }^{3}$, Andrzej Garbacz ${ }^{4}$ \\ ${ }^{1}$ Warsaw University of Technology, Faculty of Civil Engineering, 16 Armii Ludowej av., \\ 00-637 Warsaw, Poland; k.protchenko@il.pw.edu.pl (iD)0000-0003-1357-2174 \\ ${ }^{2}$ Warsaw University of Technology, Faculty of Civil Engineering, 16 Armii Ludowej av., \\ 00-637 Warsaw, Poland; e.szmigiera@il.pw.edu.pl (iD 0000-0001-9084-2372 \\ ${ }^{3}$ Warsaw University of Technology, Faculty of Civil Engineering, 16 Armii Ludowej av., \\ 00-637 Warsaw, Poland; m.urbanski@il.pw.edu.pl (D) 0000-0002-3568-6888 \\ ${ }^{4}$ Warsaw University of Technology, Faculty of Civil Engineering, 16 Armii Ludowej av., \\ 00-637 Warsaw, Poland; a.garbacz@il.pw.edu.pl (iD 0000-0002-5229-7884
}

Funding: This work was supported by the National Centre for Research and Development. Project "Innovative Hybrid FRP composites for infrastructure design with high durability” NCBR: PBS3/A2/20/2015.

Abstract: One of the main concerns that limit the widespread use of Fibre-Reinforced Polymers (FRP) bars as internal reinforcement for reinforced concrete (RC) structures is their relatively unexplored response to elevated temperatures. The behaviour of FRP reinforcement at elevated temperature as well as their post-fire behaviour can be different from conventional reinforcement and depends on the properties of the constituents of the bars. Therefore, the fire resistance of FRP-RC structures is an important issue that needs careful investigation before FRP reinforcement can be implemented in RC structures.

The experimental results for full-scale FRP-RC beams subjected to specific fire action were presented and discussed in this paper. The specimens were exposed to heat in the mid-section from below (tension zone) and from the sides. As one of the main aims was to examine the influence of different reinforcement configurations, the testing was made for concrete beams reinforced with three different types of FRP bars: (i) basalt-FRP (BFRP), (ii) hybrid FRP with carbon and basalt fibres (HFRP) and (iii) nano-hybrid FRP (nHFRP), with modification of the epoxy matrix of the rebars.

The present work describes the behaviour of FRP-RC beams exposed to fire conditions and simultaneous loading (50\% of their ultimate strength capacity at normal temperature) and unloaded beams were tested after the cooling phase in order to evaluate their residual resistance. 
Present work shows that the type of FRP bars used has a direct influence on the outcomes and the way of destruction. The maximum ductility, the longest heating time of approximately 100 minutes, was obtained for beams reinforced with BFRP bars and attained deflections were corresponded to the value of $162 \mathrm{~mm}$.

Keywords: Fibre-Reinforced Polymers (FRP) bars, Hybrid FRP bars, FRP-RC beams, Fire resistance of FRP, Fire resistance of FRP-RC members

\section{Introduction}

Implementing Fibre-Reinforced Polymers (FRP) bars as an alternative solution to traditional methods of reinforcing has become an extremely interesting issue from both theoretical and practical perspectives. FRP bars are attractive due to their advantageous properties such as durability in environments subjected to heavy corrosion, low weight while maintaining, or adequate stiffness and stability. Progress in manufacturing technology has introduced new types of FRP bars, and furthermore different hybrid FRP (HFRP) types that contain several types of reinforcing constituents and/or several types of adhesive constituents in a matrix. An important feature of HFRP bars is that the combination of its constituent allows for adjustment of their properties to a desirable design situation.

Nevertheless, the employment of FRP bars as internal reinforcement for reinforced concrete (RC) structures still poses many challenges. The bond behaviour of FRP reinforcement varies from conventional rebar due to the anisotropy of the material and a different surface texture than that of steel. In addition, FRP reinforcement displays linearly elastic behaviour up to its failure when subjected to tensile forces [1]. Other issues include a lower modulus of elasticity (for certain types) and brittle mode of failure [2]. This causes FRP bars to break without significant bending of the element, so this mode of failure is un-signalized [3]. However, some authors suggest that hybridization can partially solve this issue by changing the behaviour of FRP-RC members, making it semi-ductile instead of linear [4], [5].

The mechanical performance of FRP-RC structures is already known at ambient temperatures. One of the major issues that hinder the extensive use of FRP reinforced members is their low fire resistance, which is of high importance since building structures must satisfy the requirements of building codes, which relate to the behaviour of those structures in a fire. Fire ratings for buildings refer to the amount of time a structure can be exposed to fire before the structure collapses [6], [7]. Fire resistance of FRP-RC structures, particularly, is a multifaceted issue that considers many influencing factors, such as the critical temperature for a certain type of FRP bars, fire scenario, clear concrete cover, aggregates used for concrete mixture, etc.

The data available from standards on the behaviour of FRP, and particularly HFRP bars, at elevated temperature are scarce. ACI committee ACI 440.1R-15 [8] describes the material characteristics needed to design the minimum reinforcement regarding temperature and shrinkage thresholds. The Canadian code CAN/CSA S806-12, Annex R for slabs [9] provides a design procedure in a fire situation based on critical temperatures related to the FRP bars [10]. However, the aforementioned standards are related mainly to the most prevalent and commercially available FRP bars and do not consider hybrid bars.

In addition, several mechanical and physical characteristics of FRP bars make designing structures with FRP reinforcement different from conventional RC design in regard to fire resistance aspects [11]. Abassi and Hogg [12] performed fire tests on concrete beams reinforced with Glass-FRP(GFRP) bars with a concrete cover of about $70 \mathrm{~mm}$. The beams attained fire endurance 
for longer than $90 \mathrm{~min}$. Therefore, a minimum concrete cover of $70 \mathrm{~mm}$ was recommended for design of GFRP-RC beams under fire action.

Furthermore, the literature provides experimental results from failure tests performed on FRP reinforced concrete slabs [13]-[16] and beams [12], [17] working in flexure that were exposed in most of the cases to conventional fire conditions, e.g. simultaneous loading and heating. The outlined literature shows a need for further research regarding the post-fire behaviour of FRP-RC structures [17]. Nigro at al. [14] investigated the residual strength capacity for slabs reinforced with GFRP bars. Two unloaded slabs after heating attained deflections of approximately $70 \mathrm{~mm}$ due to their own weight and thermal strains, and their residual resistance evaluated after the cooling phase were about $55 \%$ to $100 \%$ of the ultimate design bearing moment resistance. Moreover, it was stated that the typical values of concrete clear cover (i.e. between 30 and $50 \mathrm{~mm}$ ) can be adopted.

As it is suggested in the literature, the behaviour of FRP reinforcement at elevated temperatures can be different from the conventional reinforcement and depends on the glass transition temperature of the resin. When the temperature in the resin reaches this point, it no longer becomes possible to redistribute the stresses along fibres. However, the fibres continue to withstand loading till the next threshold at which fibres begin to degrade, which is the point of failure of the structure [18]. Nevertheless, the critical temperature of FRP bars remains unknown for most of the currently available FRP-reinforcing products [14].

This study investigates the behaviour of FRP-RC beams subjected to specific fire actions, where the midsection, approximately $1 / 3$ of the length of the beams, was exposed to heating from both the bottom and sides. The experimental procedure consisted of two different cases, some samples were exposed to fire conditions and simultaneous loading ( $50 \%$ of their ultimate strength capacity at normal temperature), and for the rest of samples the residual resistance was estimated, i.e. beams were subjected to heating for approximately one hour and then unloaded. Once cooled, the beams were tested until failure. The reference beams for both cases were tested to examine the mechanical properties of the beams and compare them with the beams after being subjected to elevated temperatures.

The results of investigations were discussed with a particular emphasis on the structural behaviour of the concrete members and the types of FRP bars used.

\section{Hybrid and nano-hybrid FRP bars}

In the context of this work, the term "Hybridization" might be understood as a physical substitution of a part of fibres by another type. The proposed constituents for the hybrid bars: carbon and basalt fibres, were embedded in epoxy resin creating HC/BFRP (HFRP) bars. Processing HFRP bars is analogous to the process of producing Basalt-FRP (BFRP) bars where a certain amount of the basalt roving is replaced with carbon roving during the pultrusion process.

Prior to creating the HFRP bars, several parameters of the proposed HFRP bars were estimated, including the location of fibres, technological aspects, and the volume-fraction ratios of fibres. With that aim, the numerical and analytical considerations were made.

The properties of FRP bars in the longitudinal direction can be calculated using the Rule of Mixtures (ROM) (axial loading - Voigt model) [19]-[21]. The transverse properties can be obtained with Halpin-Tsai and other semi-empirical models [22], [23]. However, these models do not consider bars configuration, i.e. location of fibres, so, it was suggested to perform a numerical simulation. 
The numerical simulation of tensile strength test for HFRP bars was performed by Finite Element Analysis (FEA) in the software ANSYS ${ }^{\circledR}$ Academic Research Mechanical, Release 16.2 [24]. Two different bar configurations were proposed, one where carbon fibres were substituting basalt fibres in the core region, the other one with carbon fibres located in the near-surface region. In addition, different volume fractions were used to estimate their influence on the mechanical properties of HFRP bars.

The results showed that bar configuration is less important than the volume fraction of fibres. The difference between various bar configurations was shown to be a maximum of $2 \%$. Meanwhile, the volume fraction of all analyzed combinations can influence the final stiffness by $74.6 \%$.

Several technological issues were observed while placing the carbon fibres located in the near-surface region, such as increased heterogeneity in fibre locations and local scorching of the bars caused by temperature increases. Consequently, the appropriate location of carbon fibres is in the core region of the HFRP rebar.

As it is suggested in the literature, the addition of nano silica particles into the epoxy resin can improve the general performance of a composite material [25]-[27]. Therefore, it was decided to elaborate nano-Hybrid FRP (nHFRP) bars as well. A modified epoxy resin with a four-component 1300 System $^{\circledR}$ was used, which is dedicated to the manufacturing of composite materials using the pultrusion method. The sol with the nano silica particles with a concentration of 25 to $30 \%$ by weight was used. The average diameter of particles was equal to $24.7 \mathrm{~nm}$, containing two fractions: fine $(80 \%)$ and coarse $(20 \%)$.

A more detailed description of HFRP and nHFRP development is provided in the companion papers [28]-[31].

\section{Materials and experimental programme}

The experimental programme encompasses the design and fabrication of nine FRP reinforced concrete beams without any fire protection system. The investigation consisted of two different cases, Group 1 - standard fire resistance testing, the beams were subjected to loading and heating at the same time till the failure (50\% of their ultimate strength capacity at normal temperature); Group 2 - residual fire resistance testing, the beams were heated for a period of approximately one hour and then loaded till failure.

In addition, both groups were divided into two sets: set 1 with the tested beams and set 2 as reference beams. Sets 1 for both groups were preliminarily loaded, applying a gradual force until $50 \%$ of their ultimate strength capacity, and then unloaded to simulate realistic conditions, i.e. appearance of cracks. Beams from set 2 were tested with four-point flexural tests without preliminary loading and were not exposed to elevated temperatures. Table 1 shows the description of the specimens used in the tests depending on the set. 
Table 1. Descriptions of the Specimens. Source: own study

\begin{tabular}{|c|c|c|c|}
\hline \multirow[t]{2}{*}{ Set No. } & $\begin{array}{l}\text { Beam } \\
\text { designation* }\end{array}$ & $\begin{array}{l}\text { Reinforcement type } \\
\text { (tension zone) }\end{array}$ & $\begin{array}{l}\text { Preliminary loaded } \\
(50 \% \text { of ultimate load })\end{array}$ \\
\hline & & [Items / Ø / Type] & {$[\mathrm{kN}]$} \\
\hline \multicolumn{4}{|c|}{ GROUP 1 - Standard fire resistance testing \& GROUP 2 - Residual fire resistance testing } \\
\hline \multirow{3}{*}{1} & $\mathrm{~B} 2 \varnothing 14$ & $2 / 14$ / BFRP & 30 \\
\hline & $\mathrm{H} 2 \varnothing 14$ & $2 / 14$ / HFRP & 40 \\
\hline & $\mathrm{N} 2 \varnothing 14$ & $2 / 14$ / nHFRP & 40 \\
\hline \multirow{3}{*}{$\begin{array}{c}2 \\
\text { (reference samples) }\end{array}$} & $\mathrm{B} 2 \varnothing 14$ & $2 / 14$ / BFRP & 0 \\
\hline & $\mathrm{H} 2 \varnothing 14$ & $2 / 14$ / HFRP & 0 \\
\hline & $\mathrm{N} 2 \varnothing 14$ & $2 / 14 /$ nHFRP & 0 \\
\hline
\end{tabular}

* B - reinforced with BFRP bars; $\mathrm{H}$ - reinforced with HFRP bars; $\mathrm{N}$ - reinforced with FRP bars

All specimens had the same section dimensions: $140 \mathrm{~mm}$ wide, $260 \mathrm{~mm}$ high and were $3200 \mathrm{~mm}$ long. The clear cover was equal to $30 \mathrm{~mm}$ from all sides for all tested specimens.

The beams were reinforced solely with FRP bars, three different types of FRP bars were used for the tensile zone: (i) BFRP, (ii) HFRP and (iii) nHFRP bars; reinforcement ratio $0.98 \%$ was constant for all samples. The compression zone and shear reinforcement were kept constant for all the beams and were reinforced with two BFRP bars with diameters of $8 \mathrm{~mm}$. The stirrups were made of BFRP with a diameter of $6 \mathrm{~mm}$ and spacing of $100 \mathrm{~mm}$ for all the beams. The stirrups for the mid part were omitted to simulate clear bending. Figure 1 shows the scheme of tested specimens.

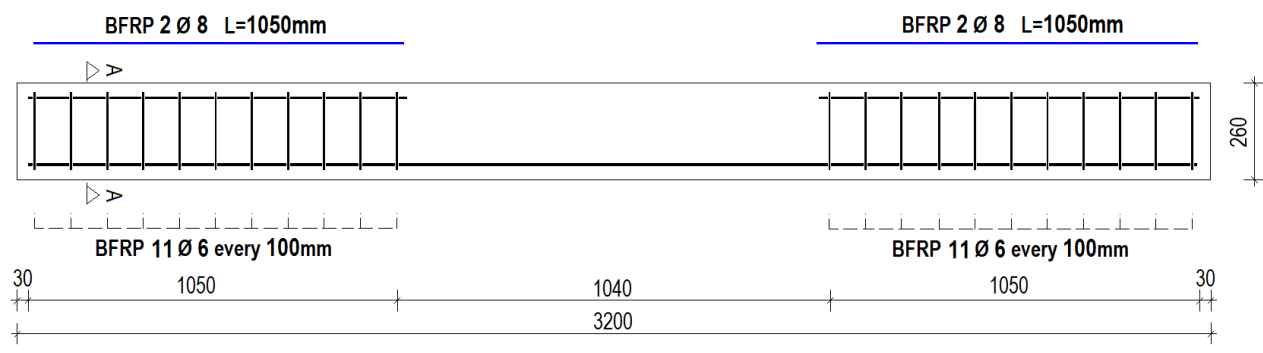

* -a- means BFRP, HFRP or nHFRP (see table below)

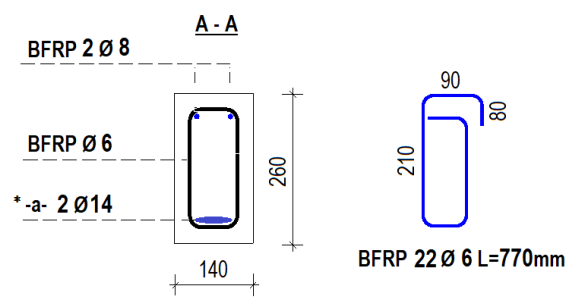

\begin{tabular}{|c|c|c|c|c|}
\hline \multicolumn{5}{|c|}{ * -a- 2 ø14 L=3140mm } \\
\hline $\begin{array}{l}\text { Beam } \\
\text { designation }\end{array}$ & $\begin{array}{l}\text { Number } \\
\text { of bars }\end{array}$ & $\varnothing$ & $\begin{array}{l}\text { Reinforcement } \\
\text { type }\end{array}$ & $\begin{array}{c}\text { Total length } \\
{[\mathrm{mm}]}\end{array}$ \\
\hline $\mathrm{B} 2 \varnothing 14$ & \multirow{3}{*}{2} & \multirow{3}{*}{14} & BFRP & \multirow{3}{*}{6280} \\
\hline $\mathrm{H} 2 \varnothing 14$ & & & HFRP & \\
\hline $\mathrm{N} 2 \varnothing 14$ & & & nHFRP & \\
\hline
\end{tabular}

Fig. 1. Schematic details of beam specimens. Source: own study 


\subsection{Materials utilized for the work}

\subsubsection{Concrete}

The concrete mixture was the same for all beams: a typical concrete mix C40/45 was used. Ordinary Portland cement CEM III/A, ash, and crushed stone (silica) with a nominal maximum size of $16 \mathrm{~mm}$ were used in concrete mixes.

\subsubsection{Reinforcement}

A more detailed description for choosing the configuration of the bars and their characteristics are reported in the following companion papers [28]-[31]. The mechanical properties for BFRP, HFRP and nHFRP, obtained experimentally from tensile testing, are shown in Tab. 2.

Table 2. Mechanical properties of FRP bars. Source: own study

\begin{tabular}{lllll}
\hline Type of bars & $\begin{array}{l}\text { Maximum } \\
\text { tensile force }\end{array}$ & Tensile strength & $\begin{array}{l}\text { Tensile strength } \\
\text { at rupture }\end{array}$ & Modulus of elasticity \\
\hline Type / Dia & $\begin{array}{l}F_{\mathrm{u}} \\
{[\mathrm{kN}]}\end{array}$ & $\begin{array}{l}f_{\mathrm{u}} \\
{[\mathrm{MPa}]}\end{array}$ & $\begin{array}{l}\varepsilon_{\mathrm{u}} \\
{[\%]}\end{array}$ & $\begin{array}{l}E_{11} \\
{[\mathrm{GPa}]}\end{array}$ \\
\hline BFRP Ø6 & 37.07 & 1148.81 & 2.48 & 46.47 \\
\hline BFRP Ø8 & 60.03 & 1103.30 & 2.52 & 43.87 \\
\hline BFRP Ø14 & 179.26 & 1101.94 & 2.39 & 46.02 \\
\hline HFRP Ø14 & 206.57 & 1160.06 & 1.61 & 72.12 \\
\hline nHFRP Ø14 & 150.54 & 958.00 & 1.58 & 60.44 \\
\hline
\end{tabular}

\subsection{Test setup}

In order to monitor the temperature distribution, deflections and possible stretching, the beams were instrumented with thermocouples in different locations (in concrete at different depths and sections and on the bars' surface) and dial gauges (on the top side and on edges).

The furnace was located around the central part of the beam and heated $1 / 3$ of the beam length. The heating was applied from the bottom and sides. The gaps between the furnace and the beam were insulated with ceramic and rock wool. Heating was applied in accordance with standard heating curve ISO-834 (1999) [32].

The Fig. 2 demonstrates the test setup and instrumentation of the beams. 


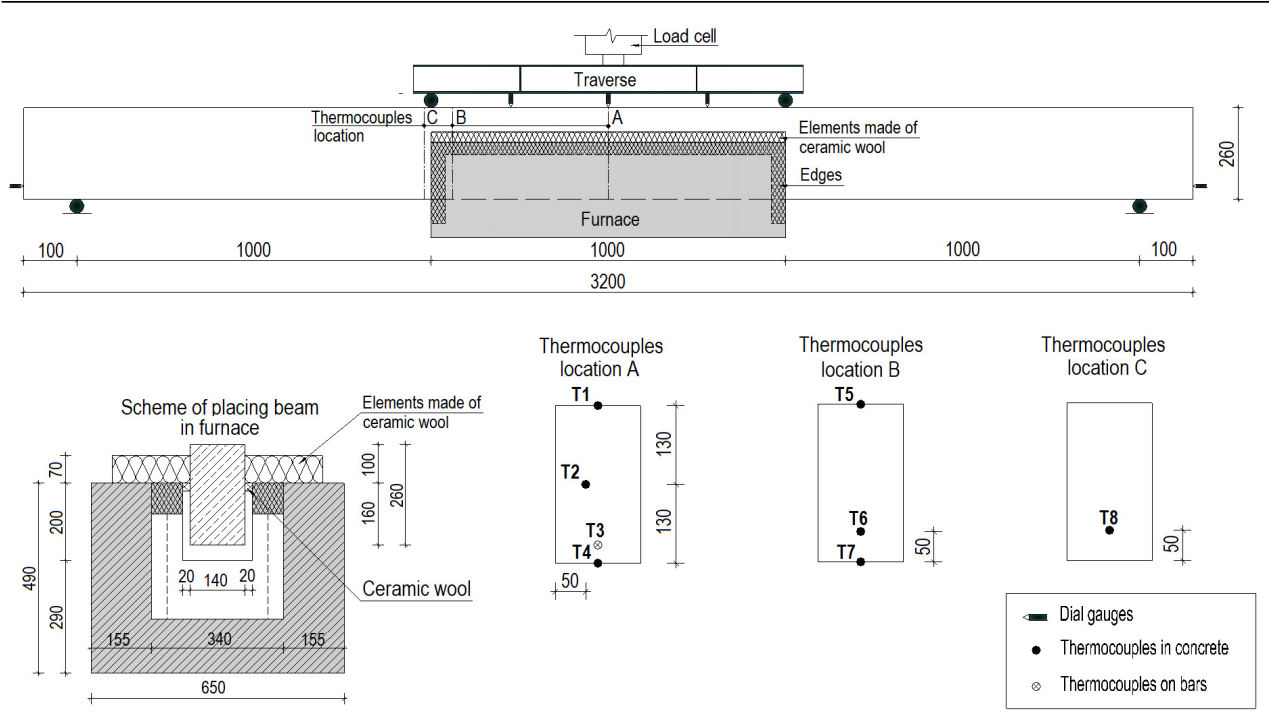

Fig. 2. Test setup description and instrumentation of the beams. Source: own study

\subsection{Standard fire resistance testing}

In the case of standard fire resistance testing, three beams of Set 1 were first loaded in the four-point flexural test with a gradual force till $50 \%$ of their ultimate strength capacity, then unloaded before being heated. The values of loading are shown in Tab. 1. Then, the beams were reloaded with sustained loading providing a bending moment that corresponds to $50 \%$ of ultimate bending moment resistance of the beams (at ambient temperature), and heating was applied. Beams were loaded and heated till failure. Set 2 was used as a reference to calculate the loading that the beams can withstand.

Beams of Set 1 were destroyed in different ways, the B2Ø14 was destroyed due to reinforcement failure, and both other beams reinforced with hybrid bars were destroyed due to concrete crushing. All the beams of the Set 2 were destroyed due to concrete crushing.

The deflections against heating duration are shown on the Fig. 3. The maximum time of fire exposure, 97 minutes, was achieved by the sample B2Ø14, once the deflection at the midspan attained a value $U_{\mathrm{B} 2 \varnothing 14}=162 \mathrm{~mm}$. The temperature recorded on the bottom side was approximately $940^{\circ} \mathrm{C}$ and $593^{\circ} \mathrm{C}$, measured directly on the bars. The displacements for the beams reinforced with hybrid bars were approximately $70 \mathrm{~mm}$ 

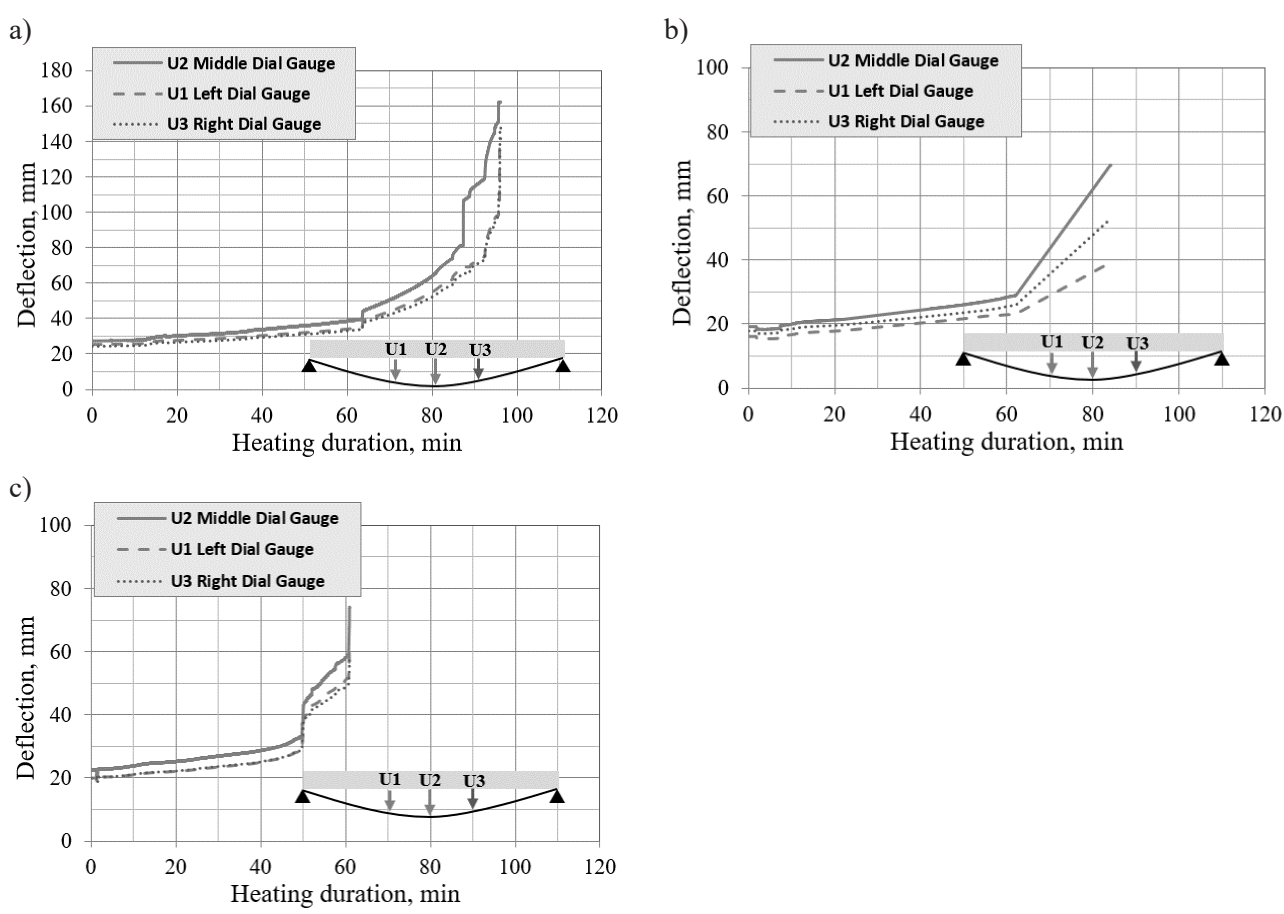

Fig. 3. Deflection - heating duration dependencies for samples (Group 1): a) B2Ø14, b) H2Ø14, c) N2Ø14. Source: own study

When the concrete cover was removed from samples $\mathrm{H} 2 \varnothing 14$ and $\mathrm{N} 2 \varnothing 14$, it could be seen that the resin evaporated from the bars. Moreover, it is visible that the temperature caused a de-bonding of the bars from the concrete. Figure 4 demonstrates the beam H2Ø14 after removing clear concrete cover. 


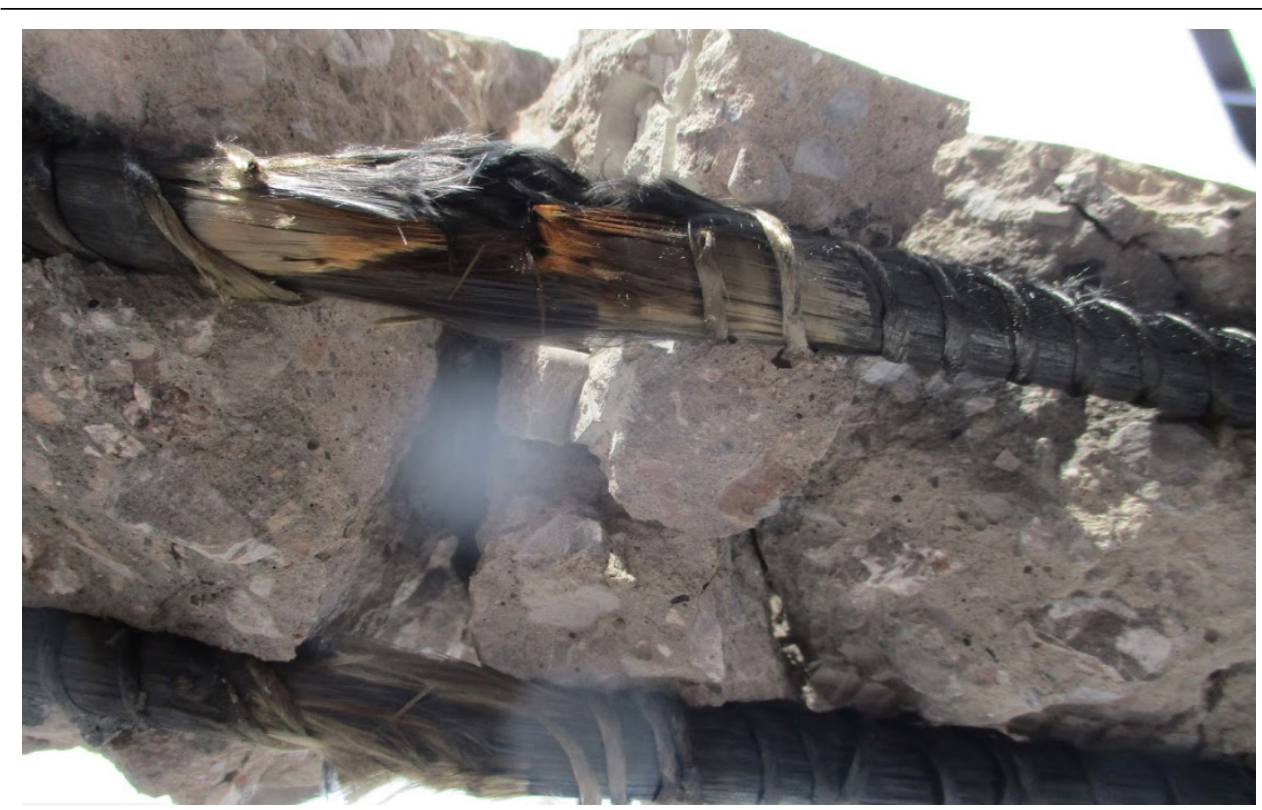

Fig. 4. Uncovered HFRP bars (by removing the clear cover after testing). Source: own study

\subsection{Residual fire resistance testing}

For residual testing, the beams of Set 1 were preliminarily loaded with a force of $50 \%$ of their ultimate strength capacity. Then the beams were unloaded. For the following steps, the beams were placed into a furnace and heated for approximately one hour. After heating, the beams were allowed to cool, and finally reloaded flexurally until failure. Figure 5 demonstrates the beam sample B2Ø14 from Set 1 just after it was taken out of the furnace.

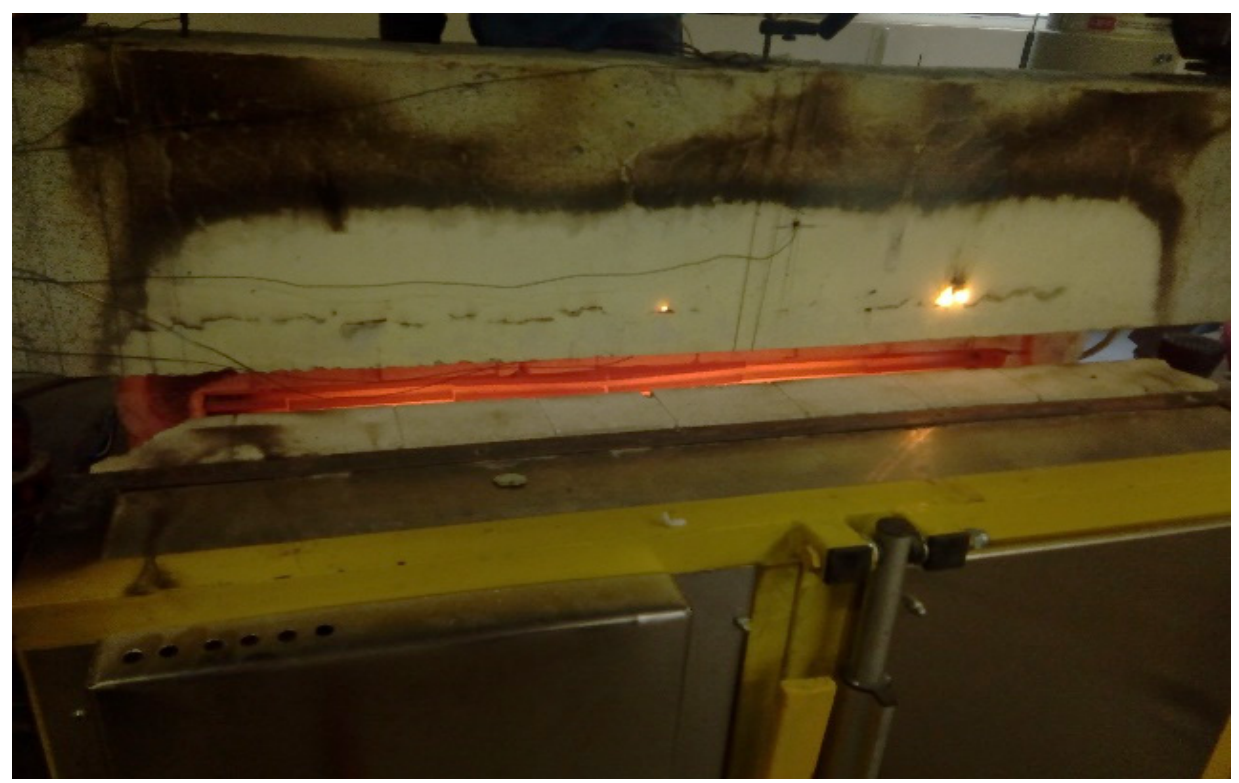

Fig. 5. Sample B2Ø14 just after taking it out from the furnace. Source: own study 
All the specimens from Set 1 were destroyed due to reinforcement failure in the tension zone, unlike beams from Set 2, where destruction took place due to concrete crushing. The authors suggest that different manners of destruction can be explained by a significant reduction in the properties of the bars after being subjected to elevated temperatures.

The evaluated resistance for beams from Set 1 after being subjected to elevated temperatures was 43.39\%, 40.34\%, and 43.42\% lower for the beams B2Ø14; H2Ø14 and N2Ø14, respectively, from Set 2 (reference beams).

Moreover, atypical behaviour of FRP-RC beams was observed while heating unloaded beams. The deflections for the beams reinforced with HFRP and nHFRP bars began to decrease after reaching a certain temperature threshold. The temperatures, measured on HFRP and nHFRP bars, were in the range of $550-570^{\circ} \mathrm{C}$. Fig. 6 demonstrates deflection - heating time dependencies for the beams subjected to residual testing.

a)

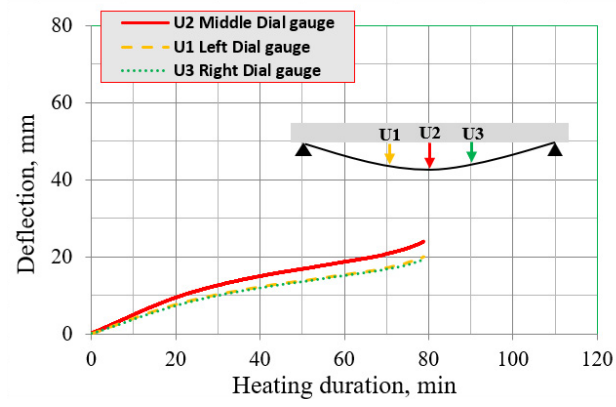

c)

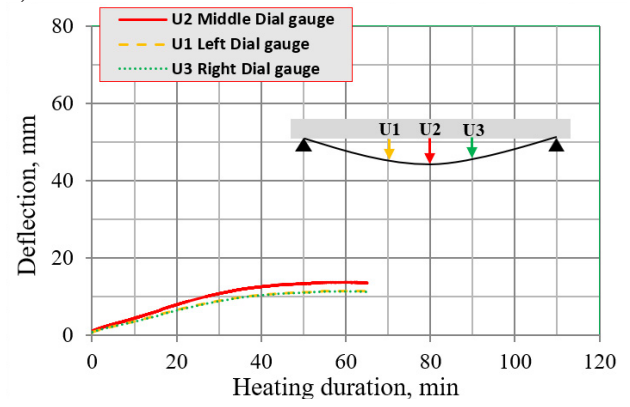

b)

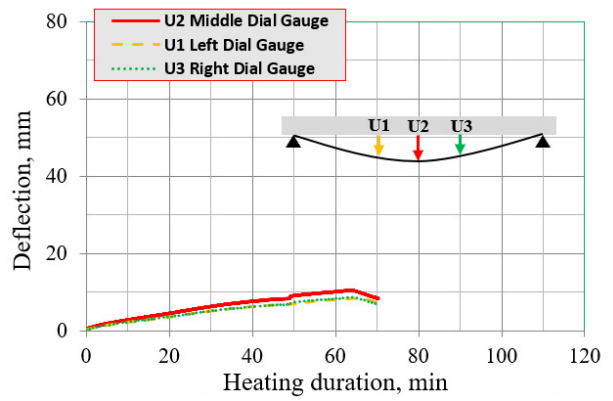

Fig. 6. Deflection - heating duration dependencies for samples (Group 2): a) B2Ø14, b) H2Ø14, c) N2Ø14. Source: own study

\section{Conclusions}

The main focus of this research was the experimental investigation of the behaviour of FRP-RC beams subjected to elevated temperatures, reflecting conditions of fire and post-fire performance of FRP-RC beams. The beams were subjected to a specific fire scenario, where the mid-part was heated.

Two cases were analyzed: (i) standard fire conditions, where loaded beams are subjected to heating and simultaneously loaded and (ii) residual behaviour of FRP-RC beams, after being subjected to elevated temperatures. 
The following conclusive remarks can be drawn:

1. Based on the maximum heating time and deflections, the best-recorded results were obtained for the samples reinforced with BFRP bars. For standard fire resistance testing, BFRP-RC beams show the longest heating time (approximately $100 \mathrm{~min}$ ) and attained the highest deflections, corresponding to the value $162 \mathrm{~mm}$.

2. Different destruction modes were observed for beams reinforced with BFRP bars and beams reinforced with hybrid bars after standard testing; for the BFRP-RC structures, the destruction was caused by a failure in the tensile zone, unlike in the other samples from Group 1 - standard testing

3. The residual capacity for the beams after being subjected to the fire exposure, decreased by approximately $40 \%$ compared to Set 2 . The highest strength capacity was obtained by beams reinforced with HFRP bars and was equal to $50.71 \mathrm{kN}$. It is worth mentioning that the post-fire behaviour of FRP-RC beams was similar as for beams not subjected to fire exposure until failure as it can be seen from the force-deflection curves.

4. Different ways of destruction, all the tested specimens from Set 1 were destroyed due to tension zone failure, unlike beams from Set 2. This can indicate a reduction of mechanical properties of FRP bars after being subjected to elevated temperatures.

5. It should be noticed that very uncharacteristic behaviour was recorded for the beams reinforced with HFRP and nHFRP bars. The authors suggest that this phenomenon is connected with the thermal expansion coefficient of the carbon fibres present in HFRP and nHFRP bars and therefore creep can appear in the bars, which causes an effect of "prestressing" of the beams.

It is worth mentioning that for a comprehensive investigation, it is needed to make more sophisticated analyses of a bigger number of samples with different fire scenario in order to receive more representative results. Current experimental work will serve to develop a program for FRP-RC members tested at and after being subjected to elevated temperatures.

\section{References}

[1] Portnov G., Bakis C.E., Lackey E., Kulakov V., "FRP Reinforcing bars - designs and methods of manufacture (Review of Patents)", Mechanics of Composite Materials, vol. 49, no. 4, (2013), pp. 381-400. https://doi.org/10.1007/s11029-013-9355-1

[2] Castro F., Protasio, Carino N., "Tensile and Nondestructive Testing of FRP Bars", Journal of Composites for Construction, vol. 2, no. 1, 1998, pp. 17-27. https://doi.org/10.1061/ (ASCE)1090-0268(1998)2:1(17)

[3] Palmieri A., Matthys S., and Tierens M. "Basalt fibres: Mechanical properties and applications for concrete structures." in Concrete solutions : proceedings of the international conference on Concrete Solutions. Taylor and Francis Group, 2009, pp.165-169.

[4] Garbacz A., Radomski W.A., Mossakowski P., "Alternatywne zbrojenie betonu kompozytami FRP - zagadnienie kompatybilności" [EN: Alternative reinforcement of concrete using FRP composites - compatibility issues], Mosty, no. 1, (2015), pp. 42-45.

[5] Elsayed T.A., Elhefnawy A.A., Eldaly A.A., Ghanem, G.M., "Hybrid fiber reinforced polymers rebars", Journal of Advanced Materials, vol. 43, 2011, pp. 65-75. https://doi.org/10.1163/092430410X547074

[6] Kowalski R., Głowacki M.J., Abramowicz M., "Premature destruction of two-span RC beams exposed to high temperature caused by a redistribution of shear forces", Journal of Civil Engineering and Manufacturing, vol. 22, no. 8, 2016, pp. 1-9. https://doi.org/10.3846/13923730.2016.1144645 
[7] Kowalski R., Głowacki M.J., "On the experimental analysis of temperature influence on stiffness of reinforced concrete beams", Journal of Structural Fire Engineering, vol. 6, no. 1, 2015, pp. 49-57. https://doi.org/10.1260/2040-2317.6.1.49

[8] ACI. Guide for the design and construction of concrete reinforced with FRP Bars. ACI 440.1R-15. Farmington Hills, MI: American Concrete Institute, 2015.

[9] CSA. Design and construction of building structures with fibre-reinforced polymers. CAN/CSA S806-12, Canadian Standards Association, 2012, Reaffirmed in 2017, 206 pages.

[10] Nigro E., Cefarelli G., Bilotta A., Manfredi G., Cosenza E., "Fire resistance of concrete slabs reinforced with FRP bars part II: experimental results and numerical simulations on the thermal field", Composites Part B: Engineering, vol. 42, no. 6, 2011, pp. 1751-1763. https://doi.org/10.1016/j. compositesb.2011.02.026

[11] Nanni A., De Luca A., Jawaheri Zadeh H., Reinforced concrete with FRP bars: Mechanics and design. CRC Press, Boca Raton, FL, 2014.

[12] Abbasi A., Hogg P.J., "Fire testing of concrete beams with fibre reinforced plastic rebar", Composites Part A, vol. 37, 2006, pp.1142-1150.

[13] Hajiloo H., Green M.F., Noël M., Bénichou N., Sultan M., "Fire tests on full-scale FRP reinforced concrete slabs", Composite Structures, vol. 179, 2017, pp. 705-719. https://doi.org/10.1016/j. compstruct.2017.07.060

[14] Nigro E., Cefarelli G., Bilotta A., Manfredi G., Cosenza E., "Fire resistance of concrete slabs reinforced with FRP bars part I: Experimental investigations on the mechanical behavior", Composites Part B Engineering, 42 (6), (2011), pp. 1739-1750. https://doi.org/10.1016/j.compositesb.2011.02.025

[15] Kodur V.K.R., Bisby L.A., Foo S., "Thermal behaviour of fire-exposed concrete slabs reinforced with fibre reinforced polymer bars", ACI Structural Journal, vol. 102, no. 6, 2005, pp. 799-807.

[16] Nigro E., Cefarelli G., Bilotta A., Manfredi G., Cosenza E., "Tests at high temperatures on concrete slabs reinforced with bent FRP bars", in Proc., $10^{\text {th }}$ International symp on fiber reinforced polymer reinforcement for reinforced concrete structures, ACI SP-275, Farmington Hills Michigan, USA, 2011.

[17] Sadek A., El-Hawary M., El-Deeb A., "Fire Resistance Testing of Concrete Beams Reinforced by GFRP Rebars", European Journal of Scientific Resources, vol. 15, no. 2, 2006, pp. 190-200.

[18] Protchenko K., Szmigiera E.D., Urbański M., Garbacz A., Narloch P.L., \& Lesniak P., "State-ofthe-Art on Fire Resistance Aspects of FRP Reinforcing Bars", IOP Conference Series: Materials Science and Engineering, vol. 661, 2019, pp. 1-8. http://doi.org/10.1088/1757-899X/661/1/012081

[19] Barbero E.J., Introduction to composite materials design. 2nd ed., Taylor \& Francis Group: Boca Raton, USA, 2011.

[20] Black T., Kosher R., "Non Metallic Materials: Plastic, Elastomers, Ceramics and Composites", in Materials and Processing in Manufacturing. $10^{\text {th }}$ ed., John Wiley \& Sons, USA, (2008), pp. 162-194.

[21] Voigt W., "Uber die beziehung zwischen den beiden elasticitatsconstanten isotroperkorper", Annals of Physics, vol. 274, no. 12, 1889, pp. 573-587.

[22] Ashton J.E., Halpin J.C., Petit P.H., Primer on composite materials: analysis. Technomic, Stamford Conn., 1969.

[23] Halpin J.C. "Stiffness and expansion estimates for oriented short fiber composites", Journal of Composite Materials, vol. 3, 1969, pp. 732-734. https://doi.org/10.1177/002199836900300419

[24] ANSYS $^{\circledR}$ Academic Research Mechanical, Release 16.2, Help System, Coupled Field Analysis Guide, ANSYS, Inc.

[25] Jesionowski T., Pilawka R., "Epoxy composites with silica crosslinked with 1-ethylimidazole" Polymers, vol. 11, no. 1, 2011, pp. 14-17. 
[26] Baur J.W., Chen C., Justice R.S., Schaefer D.W., "Highly dispersed nanosilica-epoxy resins with enhanced mechanical properties", Polymers, vol. 49, 2008, pp. 3805-3815.

[27] Jesionowski T., Pilawka R., “Kompozycje epoksydowe z krzemionką", Kompozyty, vol. 9, no. 2, 2009, pp. 112-116.

[28] Szmigiera E., Protchenko K., Urbański M., Garbacz A., "Mechanical Properties of Hybrid FRP Bars and Nano-Hybrid FRP Bars", Archives of Civil Engineering, vol. 65, no. 1, 2019, pp. 97-110. https://doi.org/10.2478/ace-2019-0007

[29] Garbacz A., Szmigiera E.D., Protchenko K., Urbański M. "On Mechanical Characteristics of HFRP Bars with Various Types of Hybridization", in Intern. Congr. on Polym. in Con. (ICPIC 2018): Polym. for Res. and Sust. Con. Infr., 2018, pp. 653-658. http://dx.doi.org/10.1007/978-3319-78175-4

[30] Protchenko K., Dobosz J., Urbański M., Garbacz A., "Wpływ substytucji włókien bazaltowych przez włókna węglowe na właściwości mechaniczne prętów B/CFRP (HFRP)" [Influence of the substitution of basalt fibres by carbon fibres on the mechanical behavior of B/CFRP (HFRP) bars], Czasopismo Inżynierii Lądowej, Środowiska i Architektury, JCEEA, 63, 1/1, 2016, pp. 149-156. http://doi.prz.edu.pl/pl/pdf/biis/454

[31] Protchenko K., Szmigiera E.D., Urbański M., Garbacz A. "Development of Innovative HFRP Bars", MATEC Web of Conferences, vol. 196, 2018, pp. 1-6. http://doi.org/10.1051/matecconf/201819604087

[32] ISO 834-1 (1999), Fire Resistance Tests - Elements of Buildings Construction, Part-1 General Requirements, International Organization for Standardization, Switzerland. 
